\title{
On the Distribution and Interpretation of Subjects And Their Numeral Classifiers*
}

\author{
Ruriko Kawashima \\ Cornell University \\ Hisatsugu Kitahara \\ Harvard University
}

\section{A Preliminary Assumption: The Single Constituent Hypothesis}

This paper examines the distribution of numeral classifiers (henceforth, NCs) associated with subjects, as shown in (1). ${ }^{1}$

(1) nihoniin-ga san-nin Gogh-no e-o rakusatu-sita Japanese-NOM three-CI G-GEN painting-ACC bid-successfully 'Three Japanese bid successfully for paintings by van Gogh.'

Kamio (1983) argues that a nominal phrase such as nihonjin-ga "Japanese-NOM" and its NC san-nin "three-CL" form a single constituent, by showing that they can be coordinated as in (2) (cf. Yoshida (1990)):

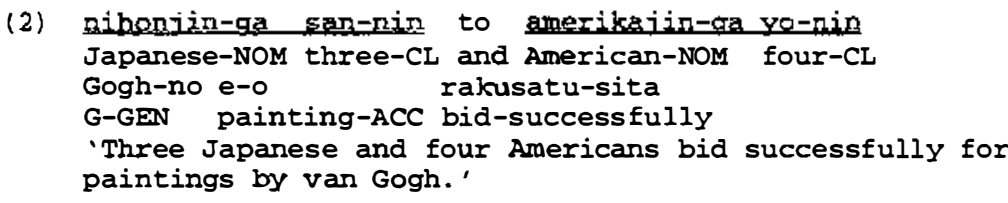

Several different analyses of the internal structure of this single constituent have been proposed (see among others, Tateishi (1989), Terada (1990), Yoshida (1990)). Kitahara (1992) proposes the structure (3) in which a head NC (whose maximal projection is selected by a head D) selects NP as a complement. ${ }^{2}$

\footnotetext{
We would like to thank Molly Diesing, Samuel D. Epstein, Fred Landman, Yafei $\mathrm{Li}$, and John Whitman for valuable comments and helpful discussion. In addition, we are grateful to Hajime Hoji, Masatoshi Koizumi, Susumu Kuno, Takashi Nakajima, Takashi Toyoshima and participants at the 3rd SALT conference for clarifying remarks and helpful suggestions. All errors are our own.

1 In Japanese, classifiers which vary according to the choice of nominals must appear with numerals.

2 Tang (1990) also proposes the same structure for nominal phrases in Chinese.

(C) 1993 by Ruriko Kawashima and Hisatsugu Kitahara

Utpal Lahiri and Adam Wyner (eds.), SALT III, 97-116, Ithaca, N.Y.: Cornell University.
} 
(3)

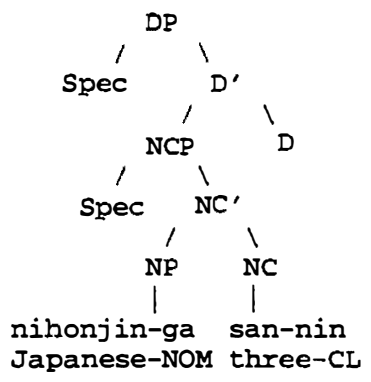

Within the framework of Case-checking (Chomsky (1992), Chomsky and Lasnik (1991)), Kitahara argues that when an overt nominal category (e.g. overt N, overt NC) bears a Case-feature, such a category is realized with an overt Case particle (in the spirit of Fukui (1986)). ${ }^{3}$ In this paper, assuming that the structure (3) is the (base-)structure of a nominal phrase and its NC, we will show that the constraint on the distribution of NCs associated with subjects (cf. Kuroda (1980)) follows from the interaction of two independently motivated principles: the ECP (Lasnik and Saito (1992)) and the Mapping Hypothesis (Diesing (1992)).

This paper consists of three sections. In section 1, Kuroda's (1980) generalization regarding the distribution of NCs associated with subjects and a problem confronting it are presented. In section 2 , we will provide a test to distinguish two interpretations of indefinite DPs (Diesing (1992)) and we will argue that this contrast is relevant to the licensing of NCs associated with subjects. In section 3, within the proposed analysis, both Kuroda's generalization and certain counter-examples to it will be shown to follow from the interaction of these independently motivated principles, namely the Mapping Hypothesis and the theory of movement.

\section{A Problem}

Kuroda (1980) observes that in Japanese, an object cannot intervene between a subject and its NC, as shown in (4).

3 Given the theory of feature-checking (Chomsky (1992), Chomsky and Lasnik (1991)), a nominal category bearing a Case-feature such as an overt NP must move to a position where its Case-feature may be checked off. We assume that the Spec of the DP whose covert head D bears a Case-feature is a position where the checking of such Case-features takes place. For empirical motivations for chis assumption, see Kitahara (1992). 
(4) a. nihonjin-ga san-nin Gogh-no e-o

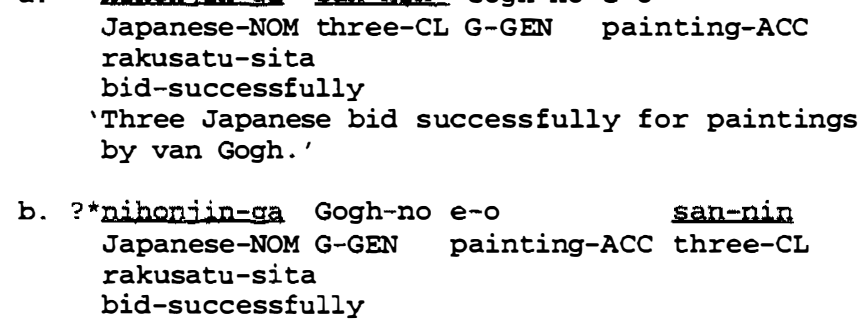

(4b), in which an object intervenes between a subject NP and its NC, is ungrammatical. Given the following two assumptions, (4b) is correctly excluded.

(5) a. An NP and its NC form a single constituent.

(Kamio (1983))

b. A subject NP cannot undergo movement from a subject position (leaving its NC behind).

(cf. Saito (1983), Sportiche (1988) $)^{4}$

(5a\&b) together entail that no item can intervene between the subject NP and its NC. Miyagawa (1989), however, points out that a temporal expression such as kinoo "yesterday" can intervene between the subject NP and its NC as shown in $(6) .5$

(6) nihonjin-ga kinoo san-nin Gogh-no e-o Japanese-NOM yesterday three-CL G-GEN painting-ACC rakusatu-sita

bid-successfully

'Three Japanese bid successfully for paintings by van Gogh yesterday.'

The grammaticality of (6) suggests that either (5a) or (5b) (or both) may be incorrect. Suppose we drop (5b) and retain (5a), assuming both the articulated single constituent analysis (i.e. structure (3)) and the VP-Internal Subject Hypothesis (cf. Kuroda (1988)). (6) is assigned structure (7). ${ }^{6}$

4 Saito (1983) argues that the subject itself cannot undergo scrambling. There are three points to note regarding the difference between Saito's assumption and our formulation of (5b): First, we refer 'movement' to A-movement (e.g. raising) in (5b) and 'scrambling' to either A or A'movement; Second, given structure (3), we call a DP a "subject" and a position the subject DP occupies a "subject position"; hence, (5b) is a condition on the movement of an NP out of a subject DP occupying the subject position; Third, we call an NP moved from the subject position a "subject NP".

5 Miyagawa (1989) proposes a non-single constituent analysis of an NP and its NC.

6 The accurate intermal structure of the subject DP in (7) is:

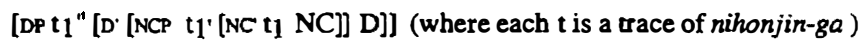




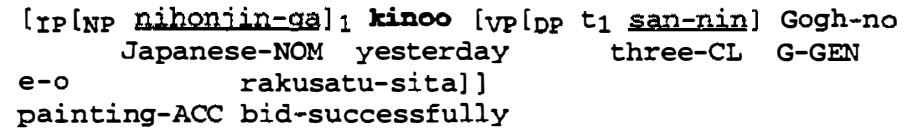

In (7) the NP nihonjin-ga "Japanese-NOM" and its NC san-nin "three-CL" form a single constituent DP occupying the Spec of VP at D-structure. Then, the NP nihonjin-ga "Japanese-NOM" is moved to the Spec of IP out of the subject DP occupying the Spec of VP. ${ }^{7}$ The subject DP occupying the Spec of VP (i.e. VPinternal) still contains the NC san-nin "three-CL" associated with the NP nihonjin-ga "Japanese-NOM." This analysis not only generates structure (7) (assigned to the grammatical (6)) but also over-generates structure (8) (assigned to the ungrammatical (4b)):

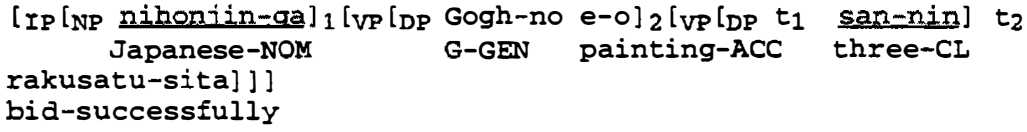

In (8), in addition to the raising of the NP from the subject DP occupying the Spec of VP (i.e. VP-internal), the object DP Gogh-no e-o "paintings by van Gogh" is scrambled i.e. adjoined to VP (cf. Saito (1985)). Thus, the problem is: While any analysis maintaining both (5a) and (5b) fails to explain the grammatical (6) (which is assigned structure (7)), the suggested analysis dropping (5b) must explain the ungrammatical (4b) (which is assigned structure (8)).

This paper takes the latter direction, that is, it eliminates the assumption (5b). We demonstrate that the contrast between the grammatical (6) (assigned (7)) and the ungrammatical (4b) (assigned (8)) follows naturally from the interaction of the theory of movement (Lasnik and Saito (1992)) and the Mapping Hypothesis (Diesing (1992)), the latter of which requires that a VP-internal subject position is associated with a non-presuppositional interpretation whereas a VP-external subject position is associated with a presuppositional interpretation. In the next section, we provide a test for presuppositional / non-presuppositional interpretation of indefinite DPs which plays an important role in our analysis.

The NP nihonjin-ga "Japanese-Nom" checks its feanures (e.g. Case, number) as it moves through Specs. In this paper, we use the simplified structure shown in (7), which is sufficient for our discussion.

7 Although we will not go into the details here, we assume that this movement is necessary for Case-checking between NP and V (for some relevant discussion of this point, see Miyagawa (1991)). 


\section{Intersentential Antecedents for Empty DPs -- A Test}

In this section, we provide a test for presuppositional / non-presuppositional interpretation of indefinite DPs. Let us begin our discussion with existential sentences in Japanese. Without any additional context, indefinite DPs preceded by locative phrases receive an existential interpretation. ${ }^{8}$ Given this, consider (9):

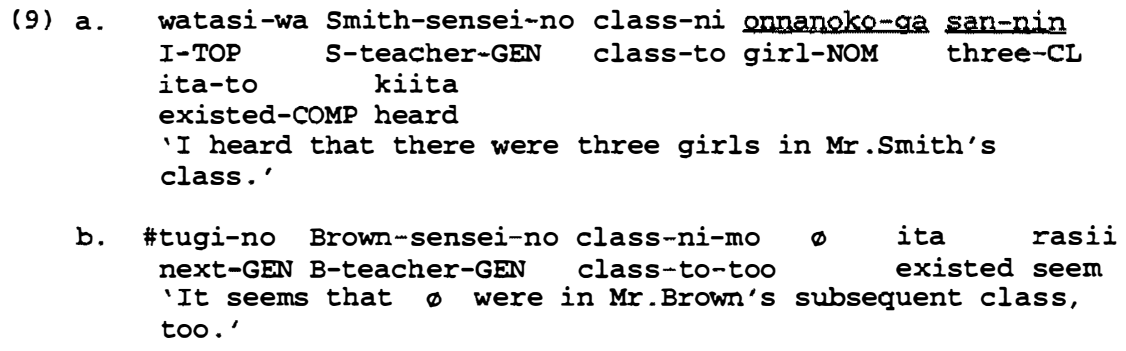

In (9a), onnanoko-ga san-nin "three girls" is preceded by a locative phrase. (9b) which contains an empty DP is unnatural as a continuation of (9a). ${ }^{9}$ We assume that this unnaturalness is due to the fact that the empty DP of (9b) fails to refer to its (potential) antecedent DP onnanoko-ga san-nin "three girls" in (9a). This problem disappears when an additional context is provided. Consider (10):

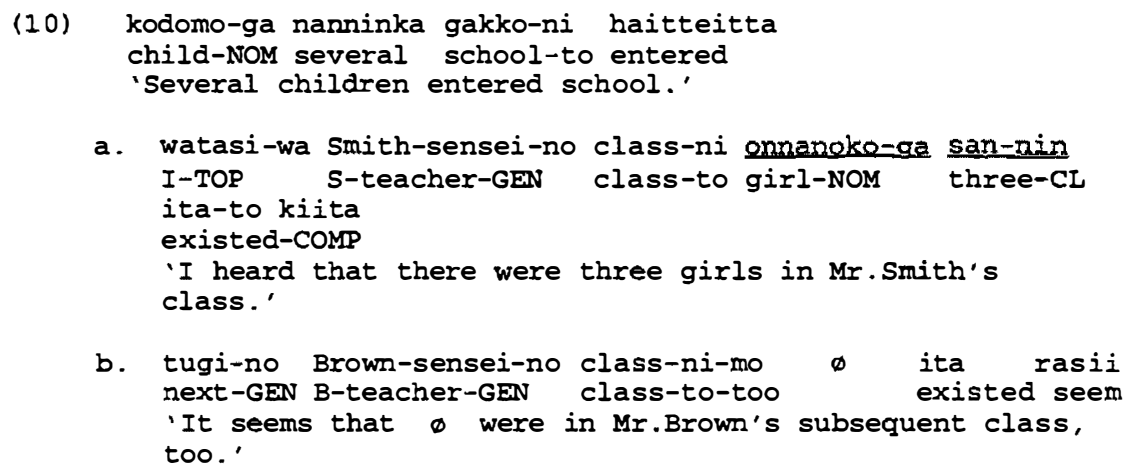

8 Existential sentences in Japanese lack overt expletives (cf. Kuno (1973), Tonoike (1992)).

9 '\#' given to sentence (9b) indicates that $(9 b)$ is unnatural as a continuation of $(9 a)$. That is, without any additional context, (9b) does not narurally follow (9a) with an empty DP referring to the same three girls who were in Mr. Smith's class. However, it is possible for the empty DP to refer to three girls different from those in Mr.Smith's class or to girls with no reference to number. We will not discuss these two readings in this paper since they are not relevant to our discussion. For some relevant discussion of these two readings which might result from VP Ellipsis, see Otani and Whitman (1991). 
In (10), given this particular context "Several children entered school," (10b) naturally follows (10a) and the empty subject DP can refer to the same three girls who were in Mr. Smith's class. In (10) (unlike (9)), the preceding sentence provides the context which introduces the set of children a subset of which is the set of girls. We assume with Enç (1991) that this context induces the partitive interpretation of the indefinite DP in (10a) which is the (potential) antecedent of the empty DP in (10b).

Provided that the 'paraphrasability' as a partitive is an indication of presuppositionality, let us assume (11) (cf. Bennis (1986), Diesing (1992)):

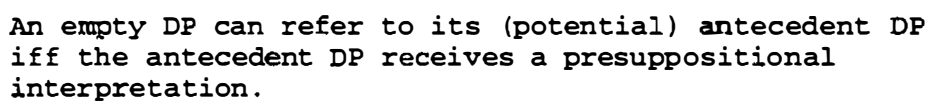

Given the Mapping Hypothesis (stated in (12)), it follows that the empty DP can refer to its (potential) antecedent DP occupying VP-external position, but it cannot refer to a (potential) antecedent DP occupying the VP-internal position at LF.

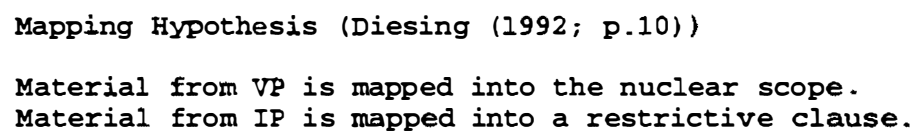

Provided that only material mapped into the nuclear scope receives a nonpresuppositional interpretation whereas only material mapped into a restrictive clause receives a presuppositional interpretation, the non-presuppositional DP of (9a) must occupy VP-internal position at LF whereas the presuppositional DP of (10a) must occupy VP-external position at LF. Thus, given conditions (11) and (12), it follows that the empty DP of (9b) cannot refer to its antecedent DP of (9a).

A similar contrast has been observed in Dutch. Bennis (1986: p.254, fn.17) notes that in Dutch, overt pronouns may refer to presuppositional indefinites, but not to non-presuppositional indefinites, providing the data in (13) (see also Diesing (1992: p.146, fn.34)):

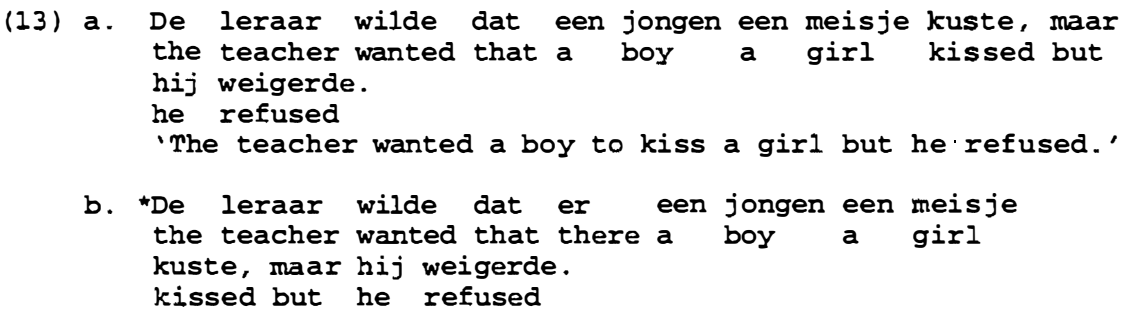


In (13b), een jongen "a boy" is in a VP-internal position as indicated by the presence of an expletive. In this case, the pronoun $h i j$ "he" cannot refer to "a boy." Assuming that empty DPs are covert pronouns in the Japanese data, the contrast in (13) provides additional support for (11) which may be restated as "pronouns can refer to its (potential) antecedent DP if and only if the antecedent DP receives a presuppositional interpretation."10, 11

\section{An Analysis}

In this section, using the antecedent test provided in the previous section, it will be shown first that the intervention between a subject NP and its NC is possible if the subject DP (which contains both the subject NP and its NC at D-structure) receives a non-presuppositional interpretation. Then, we will demonstrate that the constraint on the distribution of NCs associated with subject NPs follows from the interaction of independently motivated principles.

\subsection{Temporal Adverbs and Presuppositionality}

Assuming conditions (11) and (12), we will use our test to see whether subject DPs receive a presuppositional interpretation, occupying a VP-external position, or a non-presuppositional interpretation, occupying a VP-internal position. Consider (14):

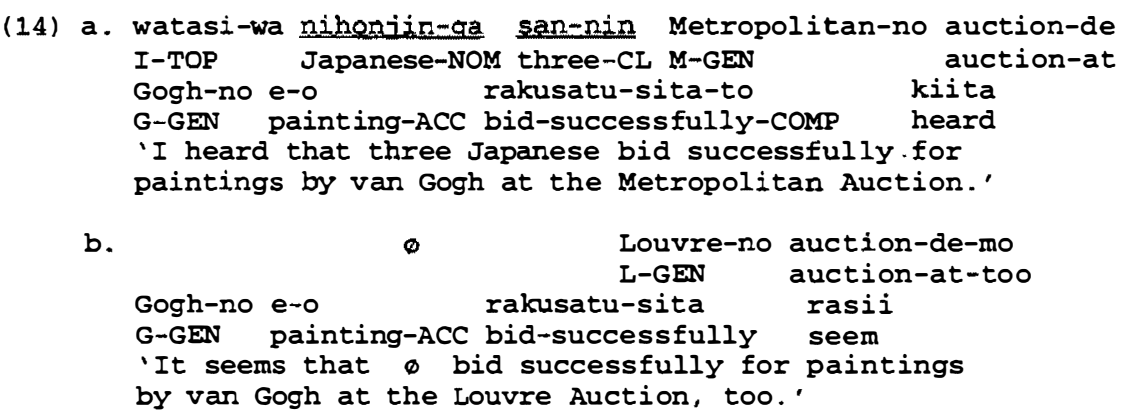

10 In this paper, we will not discuss overt pronouns such as kare "he" in Japanese which behave differently from covert pronouns (i.e. empty pronouns) (cf. Saito and Hoji (1983)). For some recent discussion of Japanese pronouns, see Noguchi (1993).

11 To some extent, this contrast holds for English. Consider the following:

(i) There is a doctor in London and he is Welsh.

This sentence cannot be used to express that there is a doctor in London who is Welsh. For more detailed discussion of (i), see Evans (1980), Heim (1982), and Kadmon (1987). 
The sentence (14b) which contains an empty subject DP naturally follows (14a). The empty subject DP of (14b) refers to the same three Japanese (who bid successfully for paintings by van Gogh at the Metropolitan Auction). Thus, given (11) and (12), the antecedent DP of (14a) occupies a VP-external subject position at LF and receives a presuppositional interpretation. Now, consider (15), where a temporal expression is added and a locative phrase precedes the indefinite subject DP:

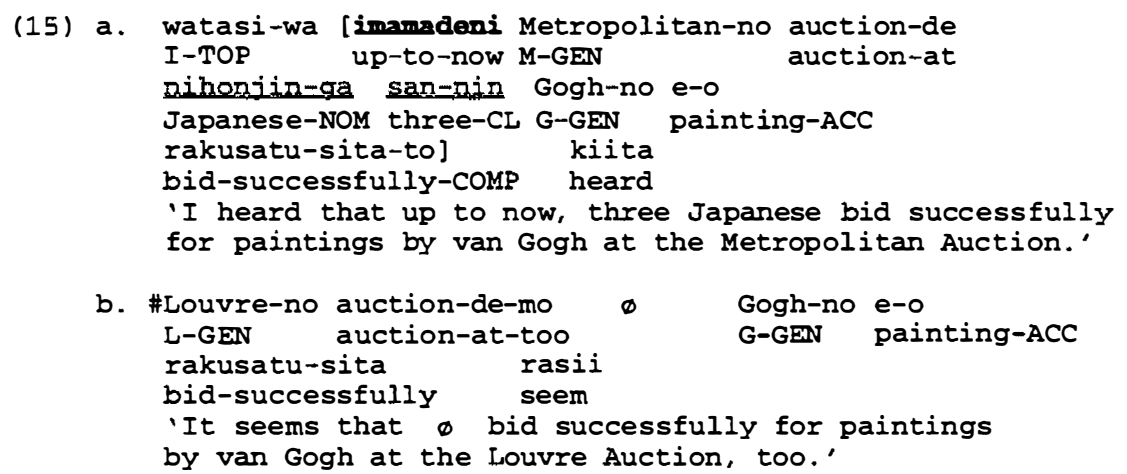

In contrast to (14b), the sentence (15b) is unnatural as a continuation of (15a). Following the discussion in section 2, we can hypothesize that this effect is due to the fact that the empty subject DP of (15b) fails to refer to its (potential) antecedent DP of (15a). Given (11) and (12), the unnaturalness of (15b) indicates that the subject DP of (15a) occupies the VP-internal subject position and receives a non-presuppositional interpretation at LF.

Suppose now that (i) the raising of the NP to the Spec of IP out of the subject DP occupying the Spec of VP and (ii) the scrambling of object DP to the VP (i.e. adjoining object DP to the VP) are both legitimate. ${ }^{12}$ Then, the proposed theory predicts that if a subject DP occupies the Spec of VP and receives a nonpresuppositional interpretation at LF (e.g. (15a)), an object DP can intervene between the subject NP and its NC. This prediction is bome out. Consider (16): 


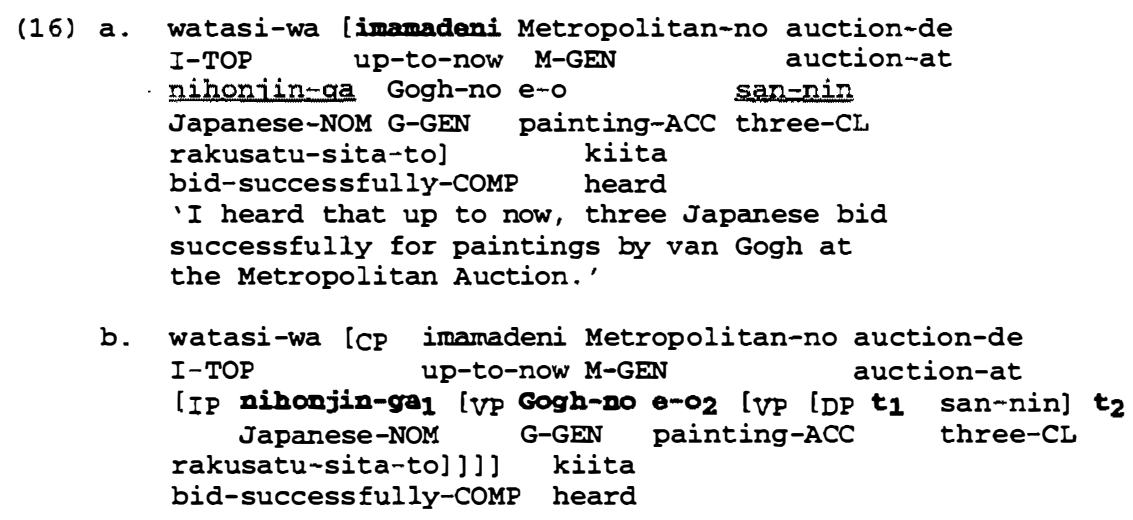

In (16a) where a temporal adverb imamadeni "up to now" and a locative phrase precede an indefinite subject DP, an object DP can indeed intervene between a subject NP and its NC (contrary to Kuroda's generalization (see (4)). ${ }^{13}$ The structure (16b) is assigned to (16a). Without such a temporal expression and with a locative phrase following the subject DP, however, an object DP cannot intervene between the subject NP and its NC (subject to Kuroda's generalization). Consider (17):

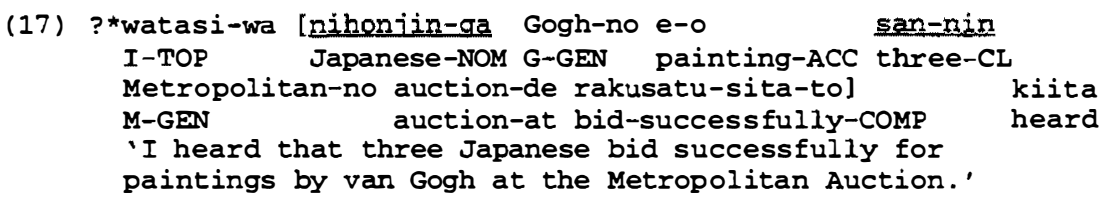

Given our analysis of (14) in which the antecedent DP of (14a) receives a presuppositional interpretation, the ungrammatical (17) shows that if a subject DP receives a presuppositional interpretation, occupying a VP-external position at LF, an object DP cannot intervene between the subject NP and its NC. ${ }^{14}$ Thus, we have the following descriptive generalizations:

13 Fukushima (1991), Fujita (1992) and Yatabe (1990) propose analyses which allow adverbs to intervene between the subject NP and its NC. Their analyses, however, would incorrectly exclude the grammatical (16).

14 In the next sub-section, we will examine structures which can be assigned to (17) and show how such structures are excluded. 
(18) a. If a subject DP receives a presuppositional interpretation, an object DP cannot intervene between the subject NP and its NC.

b. If a subject DP receives a non-presuppositional interpretation, an object DP can intervene between the subject NP and its NC.

Suppose now that the following LF structure (19), in which the subject DP occupying the Spec of VP receives a non-presuppositional interpretation (e.g. the embedded clause of (16b)), is the only legitimate structure where the object DP intervenes between a subject NP and its NC. ${ }^{15}$

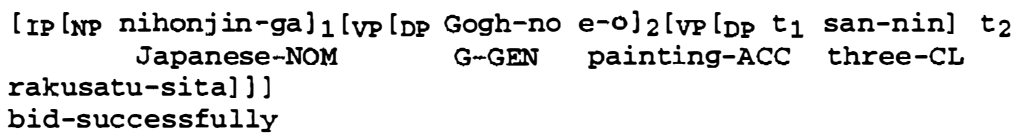

Then, the generalizations in (18) will be derived from the principles which allow (19) and exclude all other structures where the object DP intervenes between subject NP and its NC. We take this direction and show that (19) is indeed the only legitimate structure for such object DP intervention. In the next sub-section, we will demonstrate that an independently motivated theory of movement (Lasnik and Saito (1992)) excludes other possible structures.

To summarize, the grammatical (16) is problematic for previous analyses incorporating assumption (5b). Kuroda's generalization that an object DP cannot intervene between a subject NP and its NC holds if the subject DP receives a presuppositional interpretation (18a). If the subject DP receives a nonpresuppositional interpretation; however, such intervention is possible ((18b), as in (16)).

\subsection{Movement of NP out of DP and the Theory of Movement}

In the previous sub-section, we have assumed that the schematic structure (20), in which an NP is raised to the Spec of IP out of a subject DP occupying the Spec of VP $(=A)$ and an object is scrambled and adjoined to VP $(=B)$, is the only legitimate structure for the intervention of object DP:

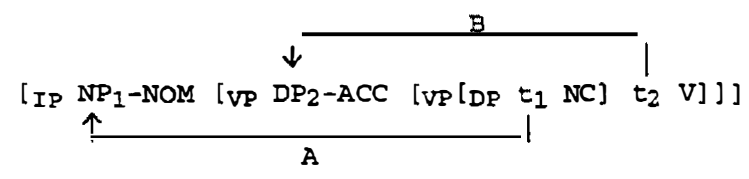

15 Regarding the Mapping Hypothesis, we assume that the NP moved out of the subject DP occupying the Spec of VP is interpreted in its trace position left in the subject DP. That is, the subject NP is mapped into the nuclear scope together with the subject DP. 
Given that scrambling can adjoin a category to IP as well (cf. Saito (1985)), the (hypothetical) representation given in (21) is also derivable:

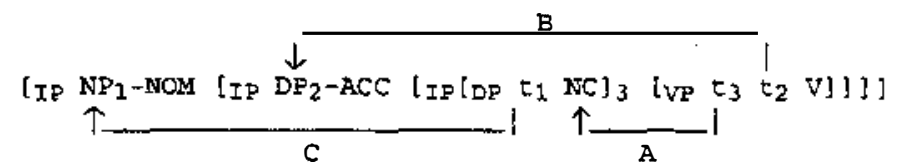

In structure (21), the (entire) subject DP is raised to the Spec of $I P(=A)$, the object DP is scrambled and adjoined to IP $(=B)$, then an NP is scrambled out of the subject DP (occupying the Spec of $I P$ ) and adjoined to $I P(=C)$. This structure would yield the LF representation in which the subject DP (occupying the Spec of IP) receives a presuppositional interpretation and the object DP intervenes between the subject NP and its NC. As the generalizations in (18) indicate, the LF structure (21) must be excluded. That is, $(20)$ is the only structure for the intervention of object DP which yields the legitimate LF representation. In this sub-section, we will show that the structure (21) is indeed ruled out by an independently motivated theory of movement (Lasnik and Saito (1992)).

Regarding extraction out of a subject, Diesing (1992), following Den Besten (1985), shows that such extraction is possible only when the subject occupies a VP-internal position, providing the contrast in the was-für split construction in German. Consider (22):

(22) a.

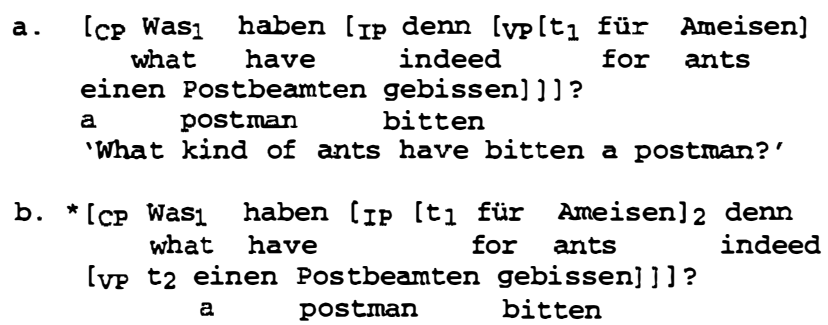

In (22a), the subject DP occupies the Spec of VP (as indicated by its occurrence to the right of a sentential particle denn "indeed") and extraction of was "what" out of the subject [was für Ameisen ] "what kind of ants" is well-formed. In (22b), however, the subject DP occupies the Spec of IP (as indicated by its occurrence to the left of the sentential particle), and such extraction is not possible.

Given the VP-internal Subject Hypothesis, we have the following generalization: "Extraction out of a category occupying a theta-marked position (e.g. VP-internal subject) is allowed whereas extraction out of a category occupying a non-theta-marked position (e.g. VP-external subject (Spec of IP)) is 
prohibited." To capture this generalization, let us assume the theory of movement adapted from Lasnik and Saito (1992). ${ }^{16}$

(23) Antecedent Government
A antecedent-governs $B$ iff
(a) $A=X^{\circ}$, and
(b) A binds $B$, and
(c) $B$ is subjacent to $A$

(24) ECP

A trace must be antecedent-governed.

Given that the ECP in (24) applies at LF (cf. Diesing (1992)), let us first consider structure (20) repeated in (25):

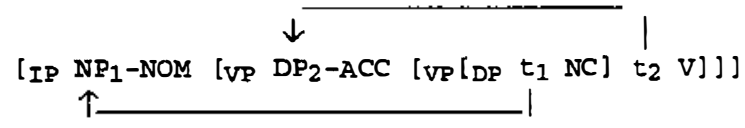

In (25), the subject DP occupying the Spec of VP is theta-marked by V', hence Lmarked (see footnote 16). The subject DP is therefore not a barrier for NP 1 at Dstructure (prior to the movement of $\mathrm{NP}_{1}$ ). $\mathrm{NP}_{1}$ moves to the Spec of IP, crossing two maximal projections, the subject DP and the two-segment category VP (cf. May (1985)). ${ }^{17}$ The moved $\mathrm{NP}_{1}$ enters into Spec-head agreement with $\mathrm{I}^{0}$. Suppose that the VP is L-marked, then there is no barrier between the trace $t_{1}$ and

16 We differ from Lasnik and Saito (1992) in the definition of L-marking stated in (iii). Crucially, we assume that Spec of VP is L-marked by V'. The relevant definitions are stated as follows:

(i) Barrier

\section{$\mathrm{Z}$ is a barrier for $\mathrm{B}$ if}

$$
\begin{aligned}
& \text { a. } \quad Z \text { is a marimal projection, and } \\
& \text { b. } \quad Z \text { is not an } A^{\prime} \text {-binder, and } \\
& \text { c. } Z \text { is not } L \text {-marked, and } \\
& \text { d. } \quad Z \text { dominates } B \text {. }
\end{aligned}
$$

(ii) $B$ is subjacent to $A$ if for every $Z, Z$ a barrier for $B$, the maximal projection immediately dominating $\mathrm{Z}$ dominates $\mathrm{A}$.

(iii) A L-marks B iff A is a (lexical) category (any bar-level projection i.e. V, V') that theta-marks $B$, and $A$ and $B$ are sisters.

17 We assume with May (1985) and Chomsky (1986) that two segments of VP together constitute a single maximal projection VP; hence a single barrier (contra Lasnik and Saito (1992)). 
its $\mathrm{X}^{0}$-binder (i.e. the head $\mathrm{I}_{1}$ ). Suppose the VP is not $\mathrm{L}$-marked, still the maximal projection IP immediately dominating the barrier VP (in the sense of Chomsky (1986) i.e. ignore $I^{\prime}$ ) dominates the $\mathrm{X}^{0}$-binder of the trace $t_{1}$ (i.e. the head $\mathrm{I}^{0}$ ). Thus, in either case, the head $I_{1}$ antecedent-governs the trace $t_{1}$. Hence, the ECP is satisfied in the LF structure (25). Let us now consider structure (21) repeated in (26):

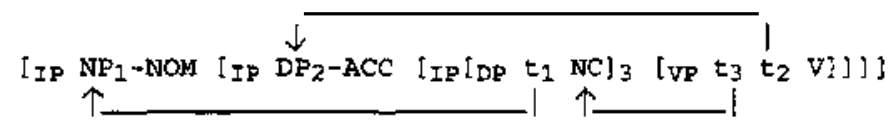

In (26), the subject DP occupying the Spec of IP is not theta-marked, hence not L-marked. ${ }^{18} \mathrm{NP}_{1}$ is scrambled out of the subject DP and adjoined to IP, crossing the barrier DP. Suppose that the adjoined $\mathrm{NP}_{1}$ does not enter into Spec-head agreement with $\mathrm{I}^{0.19}$ Then, the maximal projection IP (= the three-segment category) immediately dominating the barrier DP fails to dominate any $\mathrm{X}^{0}$-binder of the trace $t_{1}$. Thus the trace $t_{1}$ is not antecedent-governed. Hence, the ECP applying at LF excludes the structure (26).

As demonstrated above, the theory of movement allows structure (25) and excludes structure (26). Let us now recall the generalizations regarding the intervention of a scrambled object DP between a subject NP and its NC, repeated in (27):

(27) a. If a subject DP receives a presuppositional interpretation, an object DP cannot intervene between the subject NP and its NC.

b. If a subject DP receives a non-presuppositional interpretation, an object DP can intervene between the subject NP and its NC.

There are three possible cases:

(I) Suppose that a subject DP receives a presuppositional interpretation and occupies the Spec of VP at LF, then it violates the Mapping Hypothesis.

(II) Suppose that a subject DP receives a presuppositional interpretation and occupies the Spec of IP at LF, then extraction of an NP out of the subject DP at any point of the derivation yields the representation which violates the ECP at LF (i.e. (26))

18 The subject DP was theta-marked at D-structure (prior to the movement of the subject DP). Thus, theta-marking must not be carried along under movement. That is, a category is thetamarked as long as it occupies a theta-marked position.

19 The DP 3 occupying the Spec of IP enters into Spec-head agreement with $\Gamma^{0}$. 
110

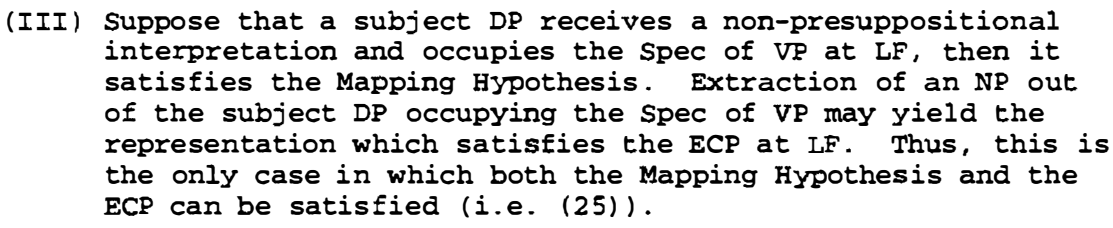

Thus, extraction of subject NP out of subject DP violates either the Mapping Hypothesis (in Case (I)) or the ECP (in Case (II)) if subject DP receives a presuppositional interpretation. In Case (III), in which a subject DP receives a non-presuppositional interpretation, however, these two principles are satisfied; hence, only in Case (III), it is possible for object DP to intervene between subject NP and its NC. The generalizations (27) are therefore deduced from the interaction of two independent principles, the Mapping Hypothesis and the ECP. 20

\subsection{Relative Clauses and Presuppositionality}

In this sub-section, we show that Miyagawa's (1989) observation that a temporal adverb e.g. kinoo "yesterday" can intervene between a subject NP and its NC is naturally subsumed under the generalizations (27). In the previous two subsections, we first made the descriptive generalizations (27) that separation is possible if a subject DP receives a non-presuppositional interpretation, occupying the Spec of VP, and then we derived the generalizations from the interaction of independent principles, the Mapping Hypothesis and the ECP. Suppose that the same condition constrains the intervention of a temporal adverb, then the proposed analysis predicts that if a temporal adverb intervenes between a subject NP and its NC, an object DP can also intervene between a subject NP and its NC. This prediction is borne out, as shown in (28):

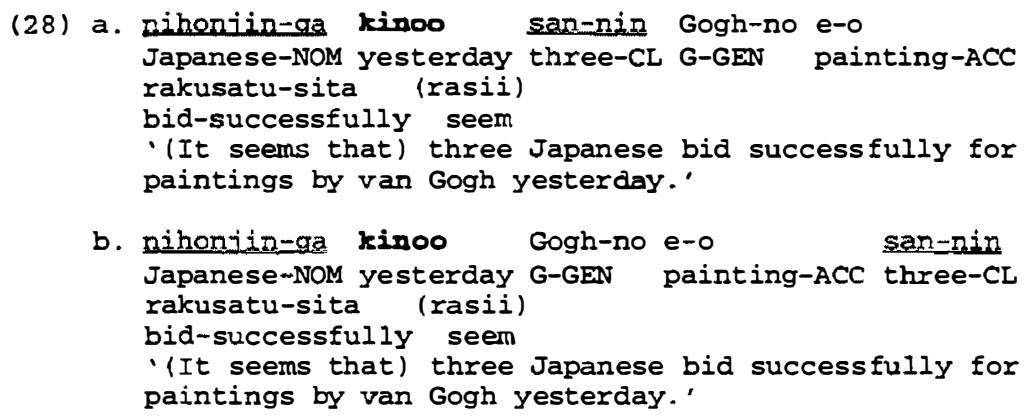

20 For the relevant discussion of the LF-application of the ECP, see Diesing (1992), Mahajan (1992). 
In (28b), not only the temporal adverb but also the object DP intervenes between subject NP and its NC (contrary to Kuroda's generalization).

The proposed analysis makes further predictions. If an indefinite DP is presupposed (by some additional factor), the theory predicts that a temporal expression (just like object DP) cannot intervene between subject NP and its NC. We will use a relative clause modifier to confirm this prediction. Let us first test whether a relative clause makes an NP presupposed or not, using the antecedent test provided in section 2. Consider (29):

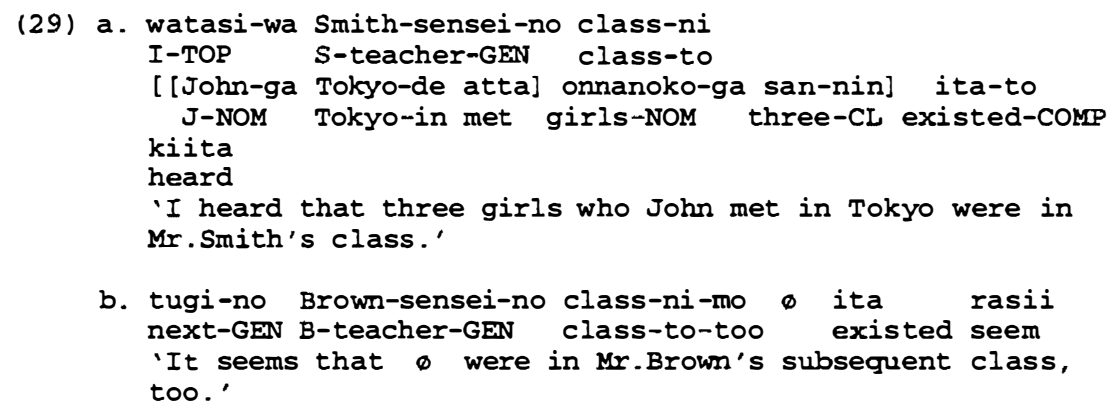

In (29a), onnanoko-ga san-nin "three girls" is modified by its relative clause modifier John-ga Tokyo-de atta "who John met in Tokyo." In this case, (29b) naturally follows (29a) and the empty DP of (29b) refers to its (potential) antecedent DP (three girls who John met in Tokyo) of (29a). Thus, given (11) and (12), the antecedent DP of (29a) occupies a VP-external position and receives a presuppositional interpretation at LF. Provided that this relative clause, which gives additional information about an indefinite DP, tends to lead the DP to be more presupposed, the proposed theory predicts that even a temporal expression such as kinoo "yesterday" may not intervene between subject NP and its NC when subject DP is modified by this relative clause which induces a presuppositional interpretation of subject DP. This prediction is also borne out. Consider (30). ${ }^{21}$

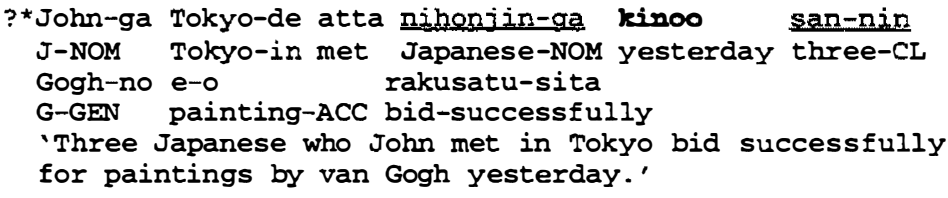

21 The sentence improves when the relative clause is understood as modifying the nominal head attributively, (i.e. expressing a property of a nominal head). In this case, the indefinite DP is not presupposed; hence, kinoo "yesterday" can intervene. 
The temporal expression, however can follow the (entire) subject DP containing its NC, as shown in (31).

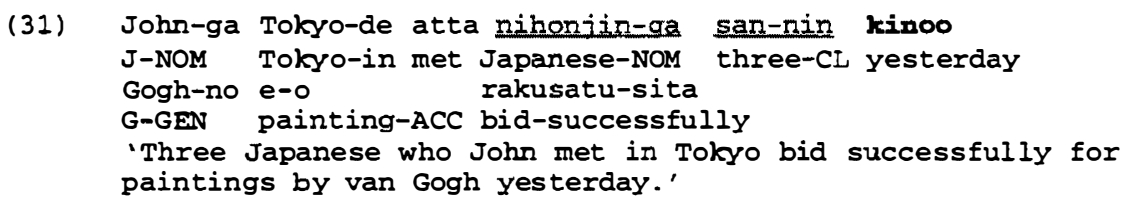

The ungrammatical sentence (30) indicates that a temporal expression such as kinoo "yesterday" (just like object DPs) can intervene between the subject NP and its NC if the subject DP receives a non-presuppositional interpretation and occupies the Spec of VP at LF and it cannot intervene between the subject NP and its NC if the subject DP receives a presuppositional interpretation (occupying the Spec of IP at LF). Miyagawa's observation regarding the intervention of a temporal expression (e.g. kinoo "yesterday") between a subject NP and its NC is thus subsumed under the generalizations (27); hence, it is explained by the interaction of the Mapping Hypothesis and the ECP.

\section{Concluding Remarks}

In this paper, Kuroda's (1980) generalization regarding the distribution of NCs associated with subjects was shown to follow from the interaction of independently motivated principles, the Mapping Hypothesis and the ECP. A test for presuppositional / non-presuppositional interpretation of indefinite DPs was provided. And a new piece of data confronting Kuroda's generalization was presented, which shows that object DP can in fact intervene between a subject NP and its NC if the subject DP receives a non-presuppositional interpretation. Miyagawa's (1989) observation that a temporal adverb can intervene between a subject NP and its NC was subsumed under the proposed generalizations. These generalizations were also shown to follow naturally from the interaction of the Mapping Hypothesis and the ECP.

\section{Appendix: On the Tense Morpheme -Ta}

A question we would like to ask in this appendix is: What properties make available a non-presuppositional interpretation of indefinite subjects? We tentatively suggest that the tense morpheme -ta plays a crucial role here. This morpheme is ambiguous between simple past and perfective interpretations (cf. Teramura (1984)). The two distinct uses of tense morpheme -ta are illustrated by two ways of negating a yes/no question, one is a past tense form and the other is a present perfective form. Consider (A1) and (A2): 
(A1) kekkyoku kimi-wa ohiru-o tabeta-no?

in-the-end you-TOP lunch-ACC ate-Q

'Did you eat lunch in the end?'
a. pro pro tabenakatta

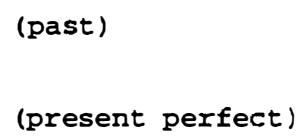

Given that the temporal phrase kekkyoku "in the end" in (A1) induces a past tense interpretation while the temporal phrase moo "already" in (A2) induces a perfective interpretation; as Teramura (1984) notes, the tense form of (A1a) (but not that of (Alb)) matches the tense of the question in (A1) while the tense form of (A2b) (but not that of (A2a)) matches the tense of the question in (A2).

Suppose that the unmarked interpretation of the tense morpheme $-t a$ is simple past which induces the presuppositional interpretation of transitive subjects, and that a temporal phrase (e.g. imamadeni "up to now," kinoo "yesterday," moo "already") makes available a perfective interpretation of tense morpheme ta which in turn makes available a non-presuppositional interpretation of transitive subjects. This analysis then predicts that if the perfective form is morphologically realized (i.e. -teiru), subject DP may receive a non-presuppositional interpretation. Consequently, object DP may intervene between subject NP and its NC. This prediction is borne out. Consider (A3) and (A4): 
(A3) Metropolitan-no auction-no kiroku-kara M-GEN auction-GEN record-from

[nibonizn-ge san-nin Gogh-no e-o

Japanese-NOM three-CL G-GEN painting-ACC

rakusatu-siteiru koto-ga] akirakani natta

bid-successfully-have KOTO-NOM clear became

'It became clear from the record of the Metropolitan auction that three Japanese have bid successfully for paintings by van Gogh.'

(A4) Metropolitan-no auction-no kiroku-kara M-GEN auction-GEN record-from

lihoniin-ga Gogh-no e-o san-nin

Japanese-NOM G-GEN painting-ACC three-CL

rakusatu-siteiru koto-ga] akirakani natta

bid-successfully-have KOTO-NOM clear became

'It became clear from the record of the Metropolitan auction that three Japanese have bid successfully for paintings by van Gogh.'

Both (A3) and (A4) contain the perfective morpheme -teiru in the embedded clause. (A4) is grammatical even though the object DP intervenes between the subject NP and its NC. Further, it is important to note that the temporal expressions such as imamadeni "up to now," kinoo "yesterday" may naturally appear with perfective morpheme as shown in (AS) and (A6):

(A5) Metropolitan-no auction-no kiroku-kara M-GEN auction-GEN record-from

[imamadoni nihoniin-qa Gogh-no e-o san-nin up-to-now Japanese-NOM G-GEN painting-ACC three-CL rakusatu-siteiru koto-ga] akirakani natta bid-successfully-have KOTO-NOM clear became

'It became clear from the record of the Metropolitan

auction that up to now, three Japanese have bid successfully for paintings by van Gogh."

(A6) Metropolitan-no auction-no kiroku-kara M-GEN auction-GEN record-from

kinoo nihonjin-ga Gogh-no e-o san-nin

yesterday Japanese-NOM G-GEN painting-ACC three-CL rakusatu-siteiru koto-ga] akirakani natta

bid-successfully-have KOTO-NOM clear became

'It became clear from the record of the Metropolitan auction that yesterday three Japanese have bid successfully for paintings by van Gogh.'

The sentences (A3) and (A4) suggest that the intervention of object DP between subject NP and its NC is possible with perfective interpretation. And the sentences (A5) and (A6) show that temporal expressions, i.e. imamadeni "up to now" and kinoo "yesterday," appear naturally with the perfect tense interpretation. 
To summarize, the two distinct uses of tense morpheme -ta (simple past, perfective) were briefly discussed. We speculated that a temporal expression such as imamadeni "up to now" makes available a perfective interpretation which induces a non-presuppositional interpretation of transitive subjects.

\section{References}

Bennis, Hans. 1986. Gaps and Dummies. Dordrecht: Foris.

Besten, Hans den. 1985. The Ergative Hypothesis and Free Word Order in Dutch and German. In Studies on German Grammar, ed. by J. Toman, 23-64. Dordrecht: Foris.

Chomsky, Noam. 1981. Lectures on Govermment and Binding. Dordrecht: Foris. . 1986. Barriers. Cambridge, MA: MIT Press. 1992. A Minimalist Program for Linguistic Theory. MrT Occasional Papers in Linguistics 1. , and Howard Lasnik. 1991. Principles and Parameters Theory. In Syntax: An International Handbook of Contemporary Research, ed. by J. Jacobs, A. van Stechow, W. Sternefeld and T. Vennemann. Berlin: Walter de Gruyter.

Diesing, Molly. 1992. Indefinites. Cambridge, MA: MIT Press.

Enç, Mürvet. 1991. The Semantics of Specificity. Linguistic Inquiry 22.1-25.

Evans, Gareth. 1980. Pronouns. Linguistic Inquiry 11.337-362.

Fujita, Naoya. 1992. Floating Quantifiers as Operators-in-Situ. Proceedings of Eastem States Conference on Linguistics 9. To appear.

Fukui, Naoki. 1986. A Theory of Category Projection and Its Applications. Cambridge: MIT dissertation

Fukushima, Kazuhiko. 1991. Phrase Structure Grammar, Montague Semantics, and Floating Quantifiers in Japanese. Linguistics and Philosophy 14 .581628.

Heim, Irene R. 1982. The Semantics of Definite and Indefinite Noun Phrases. Amherst: University of Massachusetts dissertation.

Kadmon, Nirit. 1987. On Unique and Non-Unique Reference and Asymmetric Quantification. Amherst: University of Massachusetts dissertation

Kamio, Akio. 1983. Meisiku no Koozoo. Nihongo no Kihonkoozoo, ed. by K. Inoue. Tokyo: Sanseidoo.

Kitahara, Hisatsugu. 1992. Numeral Classifier Phrases Inside DP and the Specificity Effect. Proceedings of the 3rd Japanese/Korean Linguistics Conference. To appear.

Kuno, Susumu. 1973. The Structure of the Japanese Language. Cambridge, MA: MTT Press.

Kuroda, Shige-Yuki. 1980. Bunkoozoo-no Hikaku. Bunpoo, ed. by T. Kunihiro (Nichieigo Hikaku-Kooza 2), 23-61. Tokyo: Taishyukan.

Mahajan, Anoop. 1992. The Specificity Condition and the CED. Linguistic Inquiry 23.510-516. 
May, Robert. 1985. Logical Form: Its Structure and Derivation. Cambridge, MA: MIT Press.

Miyagawa, Shigeru. 1989. Structure and Case Marking in Japanese, ed. by S. R. Anderson. (Syntax and Semantics, 22). New York: Academic Press. 1991. Case Realization and Scrambling. Cambridge, MA: MT, MS.

Noguchi, Tohru. 1993. Two Types of Pronouns and Variable Binding. Paper presented at GLOW Colloquium 16, Lund, Sweden.

Otani, Kazuyo, and John Whitman. 1991. V-Raising and VP-Ellipsis. Liguistic Inquiry 22.345-358.

Saito, Mamoru. 1983. Case and Govemment in Japanese. West Coast Conference on Formal Linguistics 2.247-259.

1985. Some Asymmetries in Japanese and Their Theoretical Consequences. Cambridge, MA: MIT dissertation.

Sportiche, Dominique. 1988. A Theory of Floating Quantifiers and its Corollaries for Constituent Structure. Linguistic Inquiry 19.425-449.

Tang, C.-C. Jane. 1990. Chinese Phrase Structure and the Extended X'-Theory. Ithaca: Cornell University dissertation.

Tateishi, Koichi. 1989. Subjects, SPEC, and DP in Japanese. North East Linguistic Society 19.405-419.

Terada, Michiko. 1990. Incorporation and Argument Structure in Japanese. Amherst: University of Massachusetts dissertation.

Teramura, Hideo. 1984. Nihongo-no Shintakusu to Imi II. Tokyo: Kuroshio.

Tonoike, Shigeo. 1992. PRO Expletive: A Case Study from Japanese Existential Sentences. Tokyo: Meiji Gakuin University, MS.

Yatabe, Shuichi. 1990. Quantifier Floating in Japanese and the Theta Hierarchy. CLS 26.437-451.

Yoshida, Tomoyuki. 1990. Sructure of the Noun Phrase in Japanese. Ithaca: Cornell University, MS.

(Ruriko Kawashima)

(Hisatsugu Kitahara) rk13@cornell.edu

kitahara@husc10.harvard.edu 